\title{
What Are the Best Questionnaires To Capture Anorectal Function After Surgery in Rectal Cancer?
}

\author{
Tina Yen-Ting Chen • Katrine J. Emmertsen • \\ Søren Laurberg
}

Published online: 27 June 2014

(C) The Author(s) 2014. This article is published with open access at Springerlink.com

\begin{abstract}
With enhanced surgical techniques and neoadjuvant therapy in rectal cancer, survivorship issues are at the forefront of clinical practice and research. More and more patients are living with altered bowel habits following rectal cancer surgery. Sound assessment of anorectal function after rectal cancer surgery is the foundation for the continuing effort to explore the adverse effects of such surgery on bowel function, as well as for working towards reducing these effects. The quality of the assessment is predominantly determined by the instrument administered. This article reviews various questionnaires for capturing anorectal function after surgery in rectal cancer, discussing their attributes and suitability for different evaluation contexts.
\end{abstract}

Keywords Rectal cancer · Rectal cancer surgery $\cdot$ Anorectal function - Anorectal dysfunction - Bowel dysfunction · Low anterior resection syndrome $\cdot$ Anterior resection syndrome . Functional outcome $\cdot$ Sphincter-preserving surgery $\cdot$ Low anterior resection - Questionnaire · Scoring system · Instrument $\cdot$ Tool $\cdot$ Assessment $\cdot$ Measurement $\cdot$ Evaluation

\section{Introduction}

Rectal cancer is common and poses much burden worldwide [1, 2]. Advances in treatment over the past three decades have led to

T. Y.-T. Chen $(\bowtie) \cdot$ K. J. Emmertsen • S. Laurberg

Department of Surgery P, Aarhus University Hospital,

Tage-Hansens Gade 2, 8000 Aarhus C, Denmark

e-mail: writetotina@gmail.com

K. J. Emmertsen

e-mail: katrineemmertsen@dadlnet.dk

S. Laurberg

e-mail: soeren.laurberg@aarhus.rm.dk substantially improved local control and survival [3-7]. Furthermore, the increasing use of sphincter-preserving resection with a low colorectal or coloanal anastomosis has resulted in fewer patients requiring a permanent colostomy, and it has become the standard surgery for mid and low rectal cancers [8-11].

Unfortunately, numerous patients experience anorectal, urinary, and/or sexual dysfunction after sphincter-preserving resection for rectal cancer [12•,13•, 14-17], with anorectal dysfunction being the commonest, especially when the surgery is combined with radiotherapy [12•, 18-23].

\section{Low Anterior Resection Syndrome}

Anorectal or bowel dysfunction after sphincter-preserving surgery manifests itself in a wide spectrum of symptoms, including fecal incontinence, increased stool frequency, urgency, and emptying difficulties. The complex of symptoms is often collectively referred to as anterior resection syndrome (ARS) or low anterior resection syndrome (LARS), named after the low anterior resection procedure [24]. Previously thought to be transient, LARS symptoms have been shown to persist for years after resection, suggesting that LARS is more of a permanent phenomenon $[13 \bullet, 25]$. These symptoms usually appear immediately after surgery, becoming most pronounced during the first few months, and improve somewhat thereafter, reaching a steady state after around one to two years [26].

Although LARS has been well recognized, it has not been clearly defined, with a large variation in the prevalence reported. LARS has been reported to affect up to $60-90 \%$ of patients following low or ultralow anterior resection [13•, 24, 27-31], and can have a considerable impact on quality of life (QOL) [26, 30, 32-35]. Recently, a pragmatic definition of 
LARS has been proposed as "disordered bowel function after rectal resection, leading to a detriment in quality of life" $[13 \bullet]$.

\section{Assessment of Anorectal Function After Rectal Cancer Surgery}

Even though anorectal function, like other types of physical function, can be evaluated objectively to a certain extent, the patient's own rating should be the gold standard, as only the patient can experience the function and perceive its true implications in the context of his or her life [36, 37]. A newly published study has demonstrated that even rectal cancer experts do not have a thorough understanding of which LARS symptoms truly matter to the patient, nor how these symptoms affect QOL, thus emphasizing the necessity of assessing anorectal function from the patient's perspective [38].

\section{Nonvalidated or Unfitting Instruments}

Many patient questionnaires or instruments have been used for assessing anorectal function after rectal cancer surgery. However, as highlighted in a systematic review and meta-analysis of long-term bowel function after curative anterior resection for rectal cancer, such assessment has been inconsistent due to the lack of a uniform definition of LARS, and the use of a large variety of nonvalidated questionnaires [12•]. It was found that 65 $\%$ of the studies included (48 studies in the qualitative analysis and 43 studies in the meta-analysis) did not use a validated assessment instrument [12•].

On the other hand, there are some anorectal function questionnaires that have been more rigorously tested, yet are not entirely suitable to be administered after surgery in rectal cancer; for instance, the American Medical Systems fecal incontinence scoring system [39], which was formulated for assessing the function of artificial anal sphincters, and the Bowel Function Questionnaire (BFQ) [40, 41], which focuses on symptoms during and after pelvic radiotherapy, as well as those caused by pharmacologic agents, instead of surgery [40-44].

A number of established bowel function-related QOL instruments, such as the European Organisation for Research and Treatment of Cancer Quality of Life Questionnaire Colorectal Module (EORTC QLQ-CR29) [45], the Fecal Incontinence Quality of Life Scale (FIQL) [46], and the Functional Assessment of Cancer Therapy - Colorectal (FACT-C) [47], have often been used to supplement the evaluation of anorectal function following surgery in rectal cancer, and to validate anorectal function questionnaires. This is because anorectal function questionnaires may only provide insight into symptoms, and not insight into how the patient is coping with the symptoms or how the patient's life is disrupted by the symptoms. Although these various QOL instruments do contain some questions enquiring directly about anorectal function, they also contain questions on other matters. More importantly, although the fundamental constructs of function and QOL are related (function, as reflected in dysfunction symptoms, is a component and determinant of overall QOL), they are not the same [48, 49], and it would be conceptually flawed to use instruments designed for measuring the effects of bowel issues on QOL to specifically capture anorectal function.

There are questionnaires that would be more appropriate than those mentioned above for capturing anorectal function after surgery in rectal cancer. The rest of this article appraises these various validated and more fitting instruments.

\section{Fecal Incontinence Instruments}

Fecal incontinence has long been the central focus of bowel dysfunction in general. In keeping with this, several wellknown fecal incontinence questionnaires have been used in different studies to evaluate incontinence in LARS patients [50-57], including the Cleveland Clinic Florida (CCF)/ Wexner Fecal Incontinence Score (Wexner score; 1993) [58], the St. Mark's Incontinence Score (St. Mark's score; 1999) [59], and the Fecal Incontinence Severity Index (FISI; 1999) [60].

The Wexner score is the most widely applied fecal incontinence instrument to date. It examines the frequency of three types of fecal incontinence (solid, liquid, and gas) and their consequences (pad wearing and lifestyle alteration). For each item, the five frequency options range from never (score 0 ) through to always (meaning at least once per day; score 4). The total score is the sum of the item scores, and ranges from 0 (perfect continence) to 20 (complete incontinence).

The St. Mark's score is built on the Wexner score, incorporating three modifications [59]. Firstly, an urgency item (lack of ability to defer defecation for $15 \mathrm{~min}$ ) was introduced, with dichotomous response options of no (score 0 ) and yes (score 4). Secondly, an item on antidiarrheal drugs (use of constipation medicines) was added, again with dichotomous response options of no (score 0 ) and yes (score 2). Lastly, it was thought that pad wearing should not be given the same emphasis as the incontinence items, because it is probably a measure of the patient's degree of fastidiousness, instead of the severity of fecal incontinence [59]. Accordingly, the response options and scoring of the pad wearing item were adjusted to no (score 0 ) and yes (score 2). The total St. Mark's score ranges from 0 (perfect continence) to 24 (complete incontinence). 
The FISI investigates the frequency of four types of fecal incontinence (gas, mucus, liquid, and solid). There are six frequency options for every item, ranging from never through to two or more times per day. The score value of each incontinence type/frequency combination is derived from its severity ranking relative to other combinations, as rated by 34 patients and 26 colorectal surgeons. Therefore, two sets of scoring are available: a patient-based system and a surgeonbased system, with the patient-based system being more broadly used. The total score is the sum of the item scores, and the patient-based score ranges from 0 (no incontinence) to 61 (severe incontinence).

All three instruments were developed empirically, on the basis of known components of fecal incontinence [58-60]. They have been validated to varying extents, with the Wexner score being the least rigorously validated of the three, despite it being the most widely used. All three instruments have been proven to correlate with the patient's subjective perception of bowel control [60-62]. They take on the same approach of assessing the frequency of incontinence episodes. This approach implies that frequency corresponds to severity, which may not always be the case. A minor symptom may occur often, but this does not mean that the symptom is severe. For example, a patient who experiences very slight leakage of liquid stool on a daily basis would score higher on these instruments compared with a patient who experiences leakage of a large amount of liquid stool every two days. The latter patient may not necessarily have better anorectal function, contrary to the impression given by these instruments.

Both the Wexner score and the St. Mark's score use a linear scale for scoring the frequency of incontinence episodes, giving zero points to a symptom never occurring, one point to it occurring rarely (less than once per month), two points to it occurring sometimes (at least once per month but less than once per week), and so forth. This kind of scale assumes that the increase in anorectal dysfunction is linear throughout the response range. It also assumes that there is a linear correlation between the frequency a the symptom and its level of bother. However, evidence shows that there is a nonlinear relationship between symptom frequency and bother in patients with neurogenic bowel dysfunction [63]. In addition, in scoring the Wexner score and the St. Mark's score, the different types of incontinence take on the same weighting, but the fact is that they (for example, incontinence for flatus vs. incontinence for solid stool) do not carry the same significance of anorectal dysfunction for either the patient or the clinician. Unlike the Wexner score and the St. Mark's score, the FISI uses patient- and surgeon-rated score values, and does not rely on a linear scale nor equalweighting scoring.

The FISI uses a one month recall period, asking the patient to answer according to how often the symptom is experienced on average in the past month. In contrast, the Wexner score and the St. Mark's score do not specify a recall period. A recall period helps to evoke the patient's memory and ensures that the most up-to-date status is captured. Nonetheless, in some situations, a recall period may result in the response not being a fair representation of the patient's usual status, such as if the patient is currently having or has recently had an infection affecting bowel function.

The most critical point to note about applying any fecal incontinence instrument to measure anorectal function after surgery in rectal cancer is that they only reveal the continence aspect. Because LARS is a disorder with heterogeneous symptoms and involves more than just incontinence, fecal incontinence instruments would not be able to fully capture the complexity of the problem.

\section{The Memorial Sloan-Kettering Cancer Center Bowel Function Instrument}

The Memorial Sloan-Kettering Cancer Center Bowel Function Instrument (MSKCC BFI; 2005) is the first questionnaire designed specifically for evaluating bowel function after sphincter-preserving surgery for rectal cancer [64••]. It consists of 18 questions that enquire about the frequency of a variety of LARS issues. The MSKCC BFI adopts a four-week recall period, a linear scale, and equal-weighting scoring. For each question, the five frequency options range from never through to always (except for one question asking about the number of bowel movements per 24 hours). Response can be summarized into three subscales (frequency, six items; diet, four items; and urgency/soilage, four items) by adding the scores of the items in the subscale. The four single items that do not belong to a subscale look into incomplete evacuation, clustering (having another bowel movement within $15 \mathrm{~min}$ of the last movement), knowing the difference between needing to pass gas and a bowel movement, and incontinence for flatus. A global score can be calculated as the sum of the subscale scores, and a total score can be calculated by adding all the item scores (subscale plus single item scores). A higher score represents better bowel function. Some item scores require recoding before they can be used for computation.

The MSKCC BFI was meticulously formulated according to literature review, expert and patient input, factor analysis, and clinical relevance [64・•]. Its psychometric precision, including the ability to detect differences in bowel function based on clinical variables, was confirmed through stringent validation [64••]. It has been translated from English into Italian, and this version has also been validated [65].

The main strengths of the MSKCC BFI are its scope and detail, allowing comprehensive and thorough evaluation of LARS. The subscales facilitate separate 
interpretation of different aspects of LARS when desired. However, the MSKCC BFI's length (18 questions) and scoring (which involves recoding, three subscale scores, a global score, and a total score) may influence its practicality.
The Low Anterior Resection Syndrome Score

The Low Anterior Resection Syndrome Score (LARS score; 2012), like the MSKCC BFI, is a questionnaire for assessing bowel function after sphincter-preserving surgery with or

\section{LARS-score - Scoring Instructions}

Add the scores from each 5 answers to one final score.

Do you ever have occasions when you cannot control your flatus (wind)?

$\begin{array}{ll}\text { No, never } & 0 \\ \text { Yes, less than once per week } & 4 \\ \text { Yes, at least once per week } & 7\end{array}$

Do you ever have any accidental leakage of liquid stool?

$\square$ No, never $\quad 0$

Yes, less than once per week 3

Yes, at least once per week $\quad 3$

How often do you open your bowels?

$\square$ More than 7 times per day (24 hours) $\quad 4$

4-7 times per day (24 hours) 2

1-3 times per day (24 hours)

Less than once per day (24 hours) $\quad 5$

Do you ever have to open your bowels again within one hour of the last bowel opening?

$\begin{array}{lr}\square \text { No, never } & 0\end{array}$

Yes, less than once per week $\quad 9$

Yes, at least once per week $\quad 11$

Do you ever have such a strong urge to open your bowels that you have to rush to the toilet?

$\square$ No, never $\quad 0$

Yes, less than once per week $\quad 11$

$\begin{array}{lr}\text { Yes, at least once per week } & 16\end{array}$

Total Score:

Interpretation:

0-20: $\quad$ No LARS

21-29: $\quad$ Minor LARS

30-42: $\quad$ Major LARS

Fig. 1 The Low Anterior Resection Syndrome Score (LARS score). (From Emmertsen and Laurberg [66••] with permission from Wolters Kluwer Health) 
without radiotherapy for rectal cancer [66••]. The items and scoring algorithm of the LARS score are shown in Fig. 1.

The LARS score was developed from and validated on a large, nationwide cohort of 961 Danish patients, who received curative low anterior resection with or without radiotherapy for nondisseminated rectal cancer in Denmark between 2001 and 2007 [66••]. By applying binomial regression on patient response, the five most bothersome LARS issues (both in terms of prevalence and impact on QOL), with at least one issue depicting each of the four known aspects of LARS (incontinence, frequency, urgency, and emptying difficulties), were selected for the LARS score from a pool of items extracted from existing bowel function questionnaires and the literature [66•*]. The five issues selected are incontinence for flatus, incontinence for liquid stool, frequency (number of daily bowel movements), clustering (having to open bowels again within $1 \mathrm{~h}$ of the last opening), and urgency. The questions enquire about the frequency of symptom episodes. The LARS score does not use a specific recall period, a linear scale, nor equal-weighting scoring. The response score values, also derived using binomial regression, are based on the impact of the particular symptom/frequency combination on QOL [66••].

The ability of the LARS score to reflect the impact of bowel dysfunction on QOL was proven in its initial validation [66••], and subsequently through the association with many of the scales of the European Organisation for Research and Treatment of Cancer Quality of Life Questionnaire Core Module (EORTC QLQ-C30) [26, 67]. The impact on QOL is pertinent when assessing bowel dysfunction, because a mere description of the symptoms may not necessarily differentiate between patients with acceptable function and patients in need of further attention. In clinical settings, the LARS score severity categories (No, Minor, and Major LARS) can facilitate quick identification of patients most in need of treatment, namely those with Major LARS, since they also report seriously compromised QOL, and significantly worse QOL compared with those with No/Minor LARS [26, 66••, 67]. Moreover, the LARS score has demonstrated the ability to differentiate between subgroups of patients on the basis of clinical variables [66••]. In addition to the original Danish version, the LARS score has been translated into several other languages (English, Dutch, Swedish, Spanish, and German: validation is in progress for the former two, and the latter three have been validated in an international setting) [68], and hence has the capacity for widespread use.

The biggest strengths of the LARS score lie in its conciseness and ability to show impact on QOL. Its ease of scoring and clinically meaningful severity categories further support its routine use in clinical practice.

Urgency and clustering are the items with the highest response score values in the LARS score, indicating that these aspects of LARS affect the patient's QOL the most. This reinforces the reasoning that fecal incontinence instruments and equal-weighting scoring would not be able to fully reflect LARS as experienced by the patient.

\section{Conclusions}

Rectal cancer surgery is now performed with relatively good oncologic outcomes and the avoidance of a permanent colostomy in most cases. Nevertheless, many patients are plagued by LARS after such surgery. Sound assessment of anorectal function after rectal cancer surgery is the foundation for continuing to elucidate the true characteristics and incidence of LARS, for further improving surgical techniques to prevent LARS, and for trialing and consolidating the treatment of LARS. The quality of the assessment lies primarily in the questionnaire used.

Given that LARS is such a common problem that often leads to poor QOL, all patients should be routinely screened for LARS after sphincter-preserving surgery, and the level of anorectal function should be systematically recorded for benchmarking and quality improvement purposes. Consequently, routine and widespread assessment of LARS is called for.

In summary, the instruments appraised in this article have strengths and weaknesses that make up their own unique "attribute profile." This profile determines the measurement context for which the instrument is most suitable.

For focused assessment of fecal incontinence, the Wexner score, the St. Mark's score, and the FISI would all be adequate. Among the three instruments, the scoring and validation of the FISI are the most methodologically rigorous. It is vital that the application of fecal incontinence questionnaires is supported by proper rationale and accurate understanding of their limitations in painting the full picture of LARS.

For comprehensive and in-depth evaluation of LARS, the MSKCC BFI would be the questionnaire of choice. For rapid screening or assessment of LARS, the LARS score would be ideal. Both instruments are valid, reliable, and able to detect clinically relevant differences.

The use of one instrument does not preclude the use of another, and there may be situations where it is beneficial to use a combination of the aforementioned instruments.

All things considered, the MSKCC BFI and the LARS score are the best questionnaires to capture anorectal function after surgery in rectal cancer. Although there is some overlap in content, the two instruments are fundamentally different. Overall, the scope of the MSKCC BFI is broader, covering not only LARS symptoms, but also their consequences, such as diet limitations and pad wearing. On the other hand, the LARS score is more practical, and can indicate impact on QOL.

Finally, the adoption of a uniform definition of LARS, and the consistent use of the same questionnaires that best serve the particular measurement context 
and aim, are greatly encouraged, in order to pool and directly compare results of different studies, institutions, and interventions.

\section{Compliance with Ethics Guidelines}

Conflict of Interest Katrine J. Emmertsen and Søren Laurberg are the original authors of the LARS score.

Tina Yen-Ting Chen has received financial support through a grant from the Boel Foundation.

Katrine J. Emmertsen has received financial support through a grant from the Danish Cancer Society.

Søren Laurberg has received financial support through a grant from the Boel Foundation.

Human and Animal Rights and Informed Consent Although the authors have previously performed studies with human and/or animal subjects, this article does not contain any new studies performed by any of the authors.

Open Access This article is distributed under the terms of the Creative Commons Attribution License which permits any use, distribution, and reproduction in any medium, provided the original author(s) and the source are credited.

\section{References}

Papers of particular interest, published recently, have been highlighted as:

- Of importance

•- Of major importance

1. International Agency for Research on Cancer. Colorectal cancer. Estimated incidence, mortality and prevalence worldwide in 2012. Available from: http://globocan.iarc.fr/Pages/fact_sheets_cancer. aspx. Accessed Jan 2014.

2. Jemal A, Bray F, Center MM, et al. Global cancer statistics. CA Cancer J Clin. 2011;61:69-90.

3. Enker WE. Total mesorectal excision - the new golden standard of surgery for rectal cancer. Ann Med. 1997;29:127-33.

4. Kapiteijn E, Putter H, van de Velde CJH, et al. Impact of the introduction and training of total mesorectal excision on recurrence and survival in rectal cancer in the Netherlands. Br J Surg. 2002;89: $1142-9$.

5. van Gijn W, Marijnen CA, Nagtegaal ID, et al. Preoperative radiotherapy combined with total mesorectal excision for resectable rectal cancer: 12-year follow-up of the multicentre, randomised controlled TME trial. Lancet Oncol. 2011;12:575-82.

6. Sebag-Montefiore D, Stephens RJ, Steele R, et al. Preoperative radiotherapy versus selective postoperative chemoradiotherapy in patients with rectal cancer (MRC CR07 and NCIC-CTG C016): a multicentre, randomised trial. Lancet. 2009;373:811-20.

7. Rutter CM, Johnson EA, Feuer EJ, et al. Secular trends in colon and rectal cancer relative survival. J Natl Cancer Inst. 2013;105:1806-13.

8. Engel AF, Oomen JL, Eijsbouts QA, et al. Nationwide decline in annual numbers of abdomino-perineal resections: effect of a successful national trial? Color Dis. 2003;5:180-4.

9. Marwan K, Staples MP, Thursfield V, et al. The rate of abdominoperineal resections for rectal cancer in the state of Victoria, Australia: a population-based study. Dis Colon Rectum. 2010;53:1645-51.
10. Tilney HS, Heriot AG, Purkayastha S, et al. A national perspective on the decline of abdominoperineal resection for rectal cancer. Ann Surg. 2008;247:77-84.

11. Stephens JH, Hewett PJ. Clinical trial assessing VSL\#3 for the treatment of anterior resection syndrome. ANZ J Surg. 2012;82:420-7.

12. Scheer AS, Boushey RP, Liang S, et al. The long-term gastrointestinal functional outcomes following curative anterior resection in adults with rectal cancer: a systematic review and meta-analysis. Dis Colon Rectum. 2011;54:1589-97. The authors identify and demonstrate that long-term bowel function after rectal cancer surgery is inconsistently assessed due to the lack of a common definition of LARS, and the use of heterogeneous, nonvalidated instruments.

13. Bryant CL, Lunniss PJ, Knowles CH, et al. Anterior resection syndrome. Lancet Oncol. 2012;13:e403-8. The authors recognize that there is no adequate instrument for measuring LARS in widespread use, and suggest a pragmatic definition of LARS to address the lack of a common definition.

14. Havenga K, Maas CP, DeRuiter MC, et al. Avoiding long-term disturbance to bladder and sexual function in pelvic surgery, particularly with rectal cancer. Semin Surg Oncol. 2000;18:235-43.

15. Havenga K, Enker WE, McDermott K, et al. Male and female sexual and urinary function after total mesorectal excision with autonomic nerve preservation for carcinoma of the rectum. J Am Coll Surg. 1996;182:495-502.

16. Engel J, Kerr J, Schlesinger-Raab A, et al. Quality of life in rectal cancer patients: a four-year prospective study. Ann Surg. 2003;238: 203-13.

17. Jayne DG, Brown JM, Thorpe H, et al. Bladder and sexual function following resection for rectal cancer in a randomized clinical trial of laparoscopic versus open technique. Br J Surg. 2005;92:1124-32.

18. Loos M, Quentmeier P, Schuster T, et al. Effect of preoperative radio(chemo)therapy on long-term functional outcome in rectal cancer patients: a systematic review and meta-analysis. Ann Surg Oncol. 2013;20:1816-28.

19. Brown LC, Atherton PJ, Neben-Wittich MA, et al. Assessment of long-term rectal function in patients who received pelvic radiotherapy: a pooled North Central Cancer Treatment Group trial analysis, N09C1. Support Care Cancer. 2013;21:2869-77.

20. Peeters KC, van de Velde CJ, Leer JW, et al. Late side effects of short-course preoperative radiotherapy combined with total mesorectal excision for rectal cancer: increased bowel dysfunction in irradiated patients - a Dutch colorectal cancer group study. J Clin Oncol. 2005;23:6199-206.

21. Lundby L, Krogh K, Jensen VJ, et al. Long-term anorectal dysfunction after postoperative radiotherapy for rectal cancer. Dis Colon Rectum. 2005;48:1343-52.

22. Dahlberg M, Glimelius B, Graf W, et al. Preoperative irradiation affects functional results after surgery for rectal cancer: results from a randomized study. Dis Colon Rectum. 1998;41:543-51.

23. Bregendahl S, Emmertsen KJ, Lous J, et al. Bowel dysfunction after low anterior resection with and without neoadjuvant therapy for rectal cancer: a population-based cross-sectional study. Color Dis. 2013;15: $1130-9$.

24. Hallböök O, Sjödahl R. Surgical approaches to obtaining optimal bowel function. Semin Surg Oncol. 2000;18:249-58.

25. Pedersen IK, Christiansen J, Hint K, et al. Anorectal function after low anterior resection for carcinoma. Ann Surg. 1986;204:133-5.

26. Emmertsen KJ, Laurberg S. Rectal Cancer Function Study Group. Impact of bowel dysfunction on quality of life after sphincterpreserving resection for rectal cancer. Br J Surg. 2013;100:137787.

27. Fazio VW, Zutshi M, Remzi FH, et al. A randomized multicenter trial to compare long-term functional outcome, quality of life, and complications of surgical procedures for low rectal cancers. Ann Surg. 2007;246:481-90. 
28. Kakodkar R, Gupta S, Nundy S. Low anterior resection with total mesorectal excision for rectal cancer: functional assessment and factors affecting outcome. Color Dis. 2006;8:650-6.

29. Ho YH, Low D, Goh HS. Bowel function survey after segmental colorectal resections. Dis Colon Rectum. 1996;39:307-10.

30. Desnoo L, Faithfull S. A qualitative study of anterior resection syndrome: the experiences of cancer survivors who have undergone resection surgery. Eur J Cancer Care (Engl). 2006;15:244-51.

31. Batignani G, Monaci I, Ficari F, et al. What affects continence after anterior resection of the rectum? Dis Colon Rectum. 1991;34:329-35.

32. Grumann MM, Noack EM, Hoffmann IA, et al. Comparison of quality of life in patients undergoing abdominoperineal extirpation or anterior resection for rectal cancer. Ann Surg. 2001;233:149-56.

33. Camilleri-Brennan J, Steele RJ. Quality of life after treatment for rectal cancer. Br J Surg. 1998;85:1036-43.

34. Camilleri-Brennan J, Ruta DA, Steele RJ. Patient generated index: new instrument for measuring quality of life in patients with rectal cancer. World J Surg. 2002;26:1354-9.

35. Pachler J, Wille-Jorgensen P. Quality of life after rectal resection for cancer, with or without permanent colostomy. Cochrane Database Syst Rev. 2012;12, CD004323.

36. Streiner DL, Norman GR. Health measurement scales: a practical guide to their development and use. 4th ed. New York: Oxford University Press; 2008.

37. McDowell I. Measuring health: a guide to rating scales and questionnaires. 3rd ed. Oxford: Oxford University Press; 2006.

38. Chen TY, Emmertsen KJ, Laurberg S. Bowel dysfunction after rectal cancer treatment: a study comparing the specialist's versus patient's perspective. BMJ Open. 2014;4:e003374.

39. American Medical Systems. Fecal incontinence scoring system. Minnetonka: American Medical Systems; 1996.

40. Atherton PJ, Halyard MY, Sloan JA, et al. Assessment of patientreported measures of bowel function before and after pelvic radiotherapy: an ancillary study of the North Central Cancer Treatment Group study N00CA. Support Care Cancer. 2013;21:1193-9.

41. Kollmorgen CF, Meagher AP, Wolff BG, et al. The long-term effect of adjuvant postoperative chemoradiotherapy for rectal carcinoma on bowel function. Ann Surg. 1994;220:676-82.

42. Kozelsky TF, Meyers GE, Sloan JA, et al. Phase III double-blind study of glutamine versus placebo for the prevention of acute diarrhea in patients receiving pelvic radiation therapy. J Clin Oncol. 2003;21:1669-74.

43. Martenson JA, Halyard MY, Sloan JA, et al. Phase III, double-blind study of depot octreotide versus placebo in the prevention of acute diarrhea in patients receiving pelvic radiation therapy: results of North Central Cancer Treatment Group N00CA. J Clin Oncol. 2008;26:5248-53.

44. Martenson JA, Bollinger JW, Sloan JA, et al. Sucralfate in the prevention of treatment-induced diarrhea in patients receiving pelvic radiation therapy: A North Central Cancer Treatment Group phase III double-blind placebo-controlled trial. J Clin Oncol. 2000;18:1239-45.

45. Whistance RN, Conroy T, Chie W, et al. Clinical and psychometric validation of the EORTC QLQ-CR29 questionnaire module to assess health-related quality of life in patients with colorectal cancer. Eur J Cancer. 2009;45:3017-26.

46. Rockwood TH, Church JM, Fleshman JW, et al. Fecal Incontinence Quality of Life Scale: quality of life instrument for patients with fecal incontinence. Dis Colon Rectum. 2000;43:9-17.

47. Yoo HJ, Kim JC, Eremenco S, et al. Quality of life in colorectal cancer patients with colectomy and the validation of the Functional Assessment of Cancer Therapy-Colorectal (FACT-C), version 4. J Pain Symptom Manag. 2005;30:24-32.

48. O'Connor R. Measuring quality of life in health. London: Churchill Livingstone; 2004.
49. Joyce CRB, O'Boyle CA, McGee HM. Individual quality of life: approaches to conceptualisation and assessment. Amsterdam: Harwood; 1999.

50. Gosselink MP, West RL, Kuipers EJ, et al. Integrity of the anal sphincters after pouch-anal anastomosis: evaluation with threedimensional endoanal ultrasonography. Dis Colon Rectum. 2005;48:1728-35.

51. Chamlou R, Parc Y, Simon T, et al. Long-term results of intersphincteric resection for low rectal cancer. Ann Surg. 2007;246:916-22.

52. Bittorf B, Stadelmaier U, Göhl J, et al. Functional outcome after intersphincteric resection of the rectum with coloanal anastomosis in low rectal cancer. Eur J Surg Oncol. 2004;30:260-5.

53. Bretagnol F, Rullier E, Laurent C, et al. Comparison of functional results and quality of life between intersphincteric resection and conventional coloanal anastomosis for low rectal cancer. Dis Colon Rectum. 2004;47:832-8.

54. Matzel KE, Stadelmaier U, Bittorf B, et al. Bilateral sacral spinal nerve stimulation for fecal incontinence after low anterior rectum resection. Int J Colorectal Dis. 2002;17:430-4.

55. Pucciani F, Ringressi MN, Redditi S, et al. Rehabilitation of fecal incontinence after sphincter-saving surgery for rectal cancer: encouraging results. Dis Colon Rectum. 2008;51: 1552-8.

56. Welsh F, McFall M, Mitchell G, et al. Pre-operative short-course radiotherapy is associated with faecal incontinence after anterior resection. Color Dis. 2003;5:563-8.

57. Gosselink MP, Zimmerman DD, West RL, et al. The effect of neorectal wall properties on functional outcome after colonic J-pouchanal anastomosis. Int J Colorectal Dis. 2007;22:1353-60.

58. Jorge JM, Wexner SD. Etiology and management of fecal incontinence. Dis Colon Rectum. 1993;36:77-97.

59. Vaizey CJ, Carapeti E, Cahill JA, et al. Prospective comparison of faecal incontinence grading systems. Gut. 1999;44:77-80.

60. Rockwood TH, Church JM, Fleshman JW, et al. Patient and surgeon ranking of the severity of symptoms associated with fecal incontinence. Dis Colon Rectum. 1999;42:1525-32.

61. Maeda Y, Parés D, Norton C, et al. Does the St. Mark's incontinence score reflect patients" perceptions? A review of 390 patients. Dis Colon Rectum. 2008;51:436-42.

62. Seong MK, Jung SI, Kim TW, et al. Comparative analysis of summary scoring systems in measuring fecal incontinence. $\mathrm{J}$ Korean Surg Soc. 2011;81:326-31.

63. Krogh K, Christensen P, Sabroe S, et al. Neurogenic bowel dysfunction score. Spinal Cord. 2006;44:625-31.

64.• Temple LK, Bacik J, Savatta SG, et al. The development of a validated instrument to evaluate bowel function after sphincterpreserving surgery for rectal cancer. Dis Colon Rectum. 2005;48: 1353-65. The authors introduce a comprehensive, detailed, and psychometrically robust instrument for examining bowel function after surgery in rectal cancer.

65. Zotti P, Del Bianco P, Serpentini S, et al. Validity and reliability of the MSKCC Bowel Function instrument in a sample of Italian rectal cancer patients. Eur J Surg Oncol. 2011;37:589-96.

$66 . \bullet$ Emmertsen KJ, Laurberg S. Low anterior resection syndrome score: development and validation of a symptom-based scoring system for bowel dysfunction after low anterior resection for rectal cancer. Ann Surg. 2012;255:922-8. The authors introduce a practical and psychometrically robust instrument for examining bowel function after surgery in rectal cancer, which reflects impact on QOL.

67. Juul T, Ahlberg M, Biondo S, et al. Low anterior resection syndrome and quality of life: an international multicenter study. Dis Colon Rectum. 2014;57:585-91.

68. Juul T, Ahlberg M, Biondo S, et al. International validation of the low anterior resection syndrome score. Ann Surg. 2014;259: 728-34. 